\title{
Marital Happiness of Married Couples in the U.A.E Society: A Sample from Sharjah
}

\author{
Dr. Husein Mohammad Al-Othman \\ Chairman of Sociology Department, University of Sharjah, UAE \\ \& Associate Professor, Faculty of Arts, Humanities \& Social Science \\ University of Sharjah, P.O. Box: 27272, W2-006-14, U.A.E \\ Tel: 971-6-505-2341_E-mail: halothman@sharjah.ac.ae, huseinothman@yahoo.com
}

Received: November 28, 2011

doi:10.5539/ass.v8n4p217
Accepted: January 9, $2012 \quad$ Published: April 1, 2012

URL: http://dx.doi.org/10.5539/ass.v8n4p217

\begin{abstract}
The goal of this study is to examine the marital happiness of married couples in Sharjah Emirate, UAE, and its determinants. To achieve these goals, data from Family Cohesion Survey (FCS) are used; a cluster sample (1136) was randomly drawn from all local families in the Emirate of Sharjah, U.A.E.; descriptive statistics (percentages, means, and standard deviations) and analytical statistics (multiple regression) are used to analyze the data set. The results of the regression analysis reveal that there are statistically significant relation between couple's communication, education, sex, residence, self-reported health, family size, and religiosity and marital happiness of married couples. However, the analysis result reveals that family income, working status, and age are silent predictors of marital happiness.
\end{abstract}

Keywords: Marriage, Happiness, Marital happiness, Family, UAE

\section{Introduction}

The family has always been at the center of life in human societies in general and Emirati society in particular. Family is formulated by legal marriage and built by children. In Arab culture, marriage is both an individual and family matter and a well-defined turning point that bestows prestige, recognition, and societal approval on both partners, especially the bride. Marriage is a social phenomena defined in the Arab culture as a legally and religious sanctioned relationship involving mutual goals, economic cooperation, intimacy, normative sexual relationship, and child bearing. Also, marital relationships involve a complex social interaction including cooperation, division of labor, conflict, and different patterns of resource allocation among spouses and their extended families.

Waite and Gallagher (2000), in their book "the Case for Marriage," they summarized 200 studies that demonstrated the major positive impacts of marriage. They found married people live longer than unmarried or divorced people, and unmarried women have $50 \%$ higher mortality rates than married women, and unmarried men have a $250 \%$ higher rate than married men (Olson, D., Defrain, J., and Skogrand, L., 2010). Also, marriage is associated with higher levels of personal well-being (Stak and Eshlemen, 1998). In addition, Waite and Gallagher (2000) indicate that married people have higher levels of psychological and physical well-being than single, separated, or divorced individuals. Furthermore, marriage may protect mental health by giving people a great sense of meaning in their lives and allowing them to fill multiple social roles (Olson et al., 2010). In the United States, there is a research evidence that married people experience higher levels of personal happiness than unmarried people (Glen and Weaver, 1979). According to Stack and Eshleman (1998), in their study for 17 industrialized nations, there is a positive relation found between marriage and happiness, and marriage might affect happiness through the promotion of financial satisfaction and the important of health. Finally, Sandhya (2009) found that in urban India, happy couples reported agreement, empathy, validation, support, and fulfilled expectations compared with unhappy couples. Couples' experience and expression of intimacy, affected by social context, also predicted enhanced levels of happiness in marriage, whereas conflict had a negative effect on marital happiness. 
Happiness is defined as a personal and subjective phenomenon (Hicks and Platt, 1970). In addition, happiness is a self-perceived subjective indicator of a positive personal feeling (Stack and Eshleman, 1998). Furthermore, Hicks and Platt, (1970) indicate that happiness, success, adjustment, and satisfaction are the terms most frequently used regarding the subjective state of the marital relationship.

The United Arab Emirates (U.A.E) has been undergoing social, economic, and political changes since the mid 1970s because of huge modernization process and planned social change. This modernization transformed the UAE society into a transitional stage where traditional values live with modern ones that affected family functions, roles, authority, and structure. The Emirati nuclear family carries many features of both western model and Arab traditional extended family model, which is characterized by extended relations. Consequently, the arranged and early marriage has been slowly declining in the Emirati society.

Research in the Arab World in general and U.A.E in particular neglected the issue of marital happiness, whereas the body of research has paid more attention to family pattern, forms of marriage, relative marriage, and the effect of work on marriage relationship. The current study is dealing with marital happiness and its determinants of independent variables found in the Family Cohesion Survey (FCS).

\section{Research Questions}

The following research questions will be addressed in this study:

1) How the married couples in Emirate of Sharjah, U. A. E., are distributed to the categories of marital happiness?

2) To what extent are the independent variables in this study (sex, place of residence, age, working status, family income, education, self-reported of health, family size, religiosity, and couple's communication) become significant predictors of the reported marital happiness of married couples in Emirate of Sharjah?

\section{Literature Review}

In U.S.A, previous empirical literature found that socioeconomic status variables are an important explanatory factor of marital happiness. For example, Corra, M., Houvounas, S., Carter, J.S., and Knox, D. (2008) found that individuals with higher income and education reported greater levels of marital happiness. Also, Glenn and Weaver (1978) mentioned that education was associated with happiness of husbands and wives (Campbell, A., Converse, P.E., and Rodgers, W.L., 1976; Gurin, G., Veroff, J., and Feld, S., 1960; Blood and Wolf, 1960; Terman, 1938). In the sixties, Hicks and Platt (1979) found positive relation between occupational status, income, and educational level for husbands in one hand and marital happiness on another. In contrast, Glenn, and Weaver (1978) found no strong positive relation between husband's occupational prestige or family income to the marital happiness of either husbands and wives. Finally, Lee and Ono (2008) found that the American couples are more likely to embrace the bargaining model where their happiness is determined by their own income. Men in the U.S. are more likely to support the specialization model; they are happier if their wives are not working or if they are financially dependent on their wives. Lee and Ono (2008) found support for the specialization model in Japan particularly in the case of women; they are happier if they are specialized in the household and they have a higher household income.

Regarding sex, many studies have shown that men report greater marital happiness than women (Lee \& Ono, 2008; Amato, P.R., Johnson, D.R., Booth, A., and Rogers, S.J., 2003; Fanlknep Davey and Darey, 2005; Henry, Miller and Giarrusso, 2005; Kaufman and Taniguch, 2006; Kiecolt-Glaser and Newton, 2001). In contrast, few studies have found contradictory results (Aldons and Woodberry, 1994). Other researchers found that sex have independent and statistically significant effects on martial happiness, with white and male respondents reporting greater levels of marital happiness than their black and female counter parts (Corra et al., 2008).

With regard to couple's communication, in a national survey of couple communication strengths in the U.S.A., Olson \& Olson (2001) found that happy couples agreed more often than unhappy couples that they were satisfied with how they talk to each other as partners, had no trouble believing each other, felt that their partners do not make comments that put them down, were not afraid to ask their partners for what they wanted, and felt free to express their true feelings to their partners. Also, Narvan (1967) found a statistically significant relation between effective communication and marital adjustment. Happily married couples had both better verbal and nonverbal communication than did unhappy couples. Additionally, there is some evidence of a positive relation between affective involvement in marriage and happiness in marriage and between open communication (Olson \& Olson, 2001). 
Age has been reported to be positively related to the overall subjective well-being of black Americans and to marital happiness (Ball and Robbins, 1984). According to Ward (1993), marital satisfaction is generally high in latter life. Also, research has shown that the relation between age and marital happiness are consistent with the curvilinear relation between the age variable and marital happiness as suggested in the literature. Marital happiness is higher in the two extremes of the age continuum. The youngest (18-24) and the oldest age groups $(75+)$ reported levels of marital happiness, which are lowest in between (Corra et al., 2008). Finally, Ward (1993) found that the reported quality of marital relationship is quite high for the older peoples.

Glenn and Weaver (1978) found religiosity highly correlated with marital happiness for whites in the U.S.A. Additionally, Richard (1993) found (for husbands) that the only statistically significant variable is frequency of church attendance. Husbands who attend church more frequently report greater marital happiness. Finally, Johnson et al., found that a self-report of strong religious commitment was associated with high marital happiness for both husbands and wives.

Research has shown that there is an association between working status, family size, self-reported health, number of children younger than 18 years, and marital happiness. For example, husband's employment is crucial to family financial support, self-esteem, and marital relations (Scanzoni, 1977; Strong \& Devault,1995). Also, a higher total number of persons in the household can be expected to have a negative effect on marital relations (Richard, 1993). In addition, numerous studies have shown health to be positively correlated with various types of subjective well-being for whites (Michalos, 1985). Research has found that having a child younger than 18 years at home was associated with significantly lower marital happiness for black husbands but not for black wives (Mclarahan \& Adnms, 1987; Umberson \& Gove, 1989). Finally, Lee and Ono (2007) found that children are related to lower levels of marital satisfaction for women in both U.S.A and Japan.

\section{Methodology}

\subsection{The sample}

In the analysis of this research, data from Family Cohesion Survey (FCS) have been used. The data were conducted by the author funded by the Graduate Studies and Research Deanship at the University of Sharjah, UAE. A cluster sample (1136) was randomly drawn from all local families in the Emirate of Sharjah. The sample's characteristics are presented in Table (1).

\subsection{Operational Measurement}

\subsubsection{Dependent Variables}

Marital happiness is measured by responses to a question used by the American General Social Survey, which is as follows: "Taking things all together, how would you describe your marriage-very happy, pretty happy, or not too happy?" "Very happy" is coded 3, "pretty happy is coded 2, and "not too happy" is coded 1. Response items, such as "don't know" and "no answer," were excluded from the analysis. Ranges, means, and standard deviation of the dependent and independent variables included in the analysis are presented in Table (2).

\subsubsection{Independent Variable}

Marital happiness has been modeled as a function of sex, place of residence, age, working status, family income, education, self-reported health, religiosity, family size, and couple's communication. The independent variables in this study were measured as shown in Table (1).

\section{Analysis and Discussions}

In the analysis of this research, descriptive and inferential statistics were used. The distribution of respondents according to their marital happiness is presented in Table (3). According to this table, the majority of married couples $(56.3 \%)$ answered that they were pretty happy in their marriage, whereas less than third of the married couples $(30.6 \%)$ classified themselves very happy in their marriage. On the other hand, $13 \%$ of the married couples perceived themselves not happy in their marriage. The result of descriptive statistics demonstrated that the majority of married couples classified themselves as very happy or pretty happy; this might be explained by the importance of marriage in the Emirati society where marriage is viewed as a social value, the integration of the traditional values with the modern ones, and the high level of standard living in the UAE. However, still, some married couples did not experience marital happiness, which might be explained by the increase in marital failure. Finally, the regression analysis will explain more of the effect of some independent variables on marital happiness in the study. 


\subsection{Multiple Linear Regression Analysis}

Multicollinearity exists when two or more independent variables are highly correlated (Vogt 1999; Lewis-Beck 1980). The correlation matrix was examined for potential signs of multicollinearity. Table (4) indicates that sex and working status are the two independent variables with the strongest bivariate correlation $(r=0.450)$. Therefore, multicollinearity is not serious among the independent variables in this study.

According to Table (5), knowledge of the independent variables in this study explains approximately $47 \%$ of the variance in the marital happiness of married couples in the Emirate of Sharjah, UAE. According to Table 5, the empirical findings in multivariate analysis indicated that couple's communication, sex, level of education, place of residence, family size, religiosity, and self-reported health variables were observed to have a statistically significant relation with marital happiness. However, age, working status, and family income were silent variables in predicting marital happiness.

According to Table (5), the observed data indicate that couple's communication has a statistically significant positive effect $(\mathrm{t}=25.492, \mathrm{p}=0.00)$ on marital happiness after controlling for the effect of other independent variables in the regression model. The partial standardized regression coefficient $\left(B^{*}=0.599\right)$ indicates that level of communication has high effect on the degree of marital happiness. Also, couple's communication was observed to have the strongest multivariate explanatory factor on marital happiness. Consequently, this finding is consistent directionally with the previous literature. Additionally, this result of the analysis assert that communication is the way humans create and share meaning, both verbally and nonverbally, and the ability to communicate is an essential skill individuals must master if they are to enjoy close relationship. The ability and the willingness to communicate is among the most important factors in maintaining a satisfying relationship, and communication in a positive manner is an important element to compromise and resolve conflicts in a constructive way and develop realistic expectations (Olson \& Olson, 2000). Consequently, couple's communication is regarded as a cross - cultural predictor of marital happiness.

The partial unstandardized regression coefficient, B, indicates that the mean level of marital happiness for males is 1.34 higher than the mean level of marital happiness for females after controlling for the effects of the other independent variables in the regression equation. However, the partial standardized regression coefficient $\left(\mathrm{B}^{*}=\right.$ 0.098 ) indicates that the effect of sex on martial happiness is very weak. The data were consistent with the previous literature. This result can be explained by the male-dominant society where marriage is better for men than women because women are expected to take care of men and play a subordinate role in the marriage institution.

According to Table (5), level of education $\left(\mathrm{B}^{*}=0.067, \mathrm{t}=2.451, \mathrm{p}=0.014\right)$ has a weak and positive relation with marital happiness. This finding is consistent with previous literature. Education may give additional resources, such as income, insight, or status, which contribute to the ability to perform marital roles. However, family income was found to be a silent variable to predict marital happiness. Glenn and Weaver (1978) indicate that higher status persons tend to have more satisfactory marriages than lower status ones, perhaps because low-status marriages are prone to a number of deficiencies such as lack of communication between spouses (Komerov, SKY, 1962). It is possible that high status contributes to success of marriage but tends to lower marital happiness by making the spouses less inclined to terminate emotionally unsatisfying marriages.

Table (5) indicates that self-reported health variable has a weak and positive effect on the degree of marital happiness $\left(B^{*}=0.162, t=6.402, p=0.000\right)$. Consequently, the result of the statistical analysis is consistent with the previous literature. This result might be explained by the positive reflection of health on marital relations. Also, family size was observed to have a weak and negative association with marital happiness $\left(\mathrm{B}^{*}=-0.083, \mathrm{t}=\right.$ $-2.977, \mathrm{p}=0.003$ ). This often is attributed to the time, effort, worry, and economic costs associated with raising children as a result of modernization process in the Emirati society. According to Table 5, there is a weak statistical association between place of residence $\left(B^{*}=0.109, t=4.624, p=0.000\right)$ and marital happiness. Urban resident is more likely than rural resident to be happier in their marital happiness because life chances are better compared with rural areas. Furthermore, religiosity is associated with marital happiness $\left(B^{*}=0.054, t=2.360, p\right.$ $=0.018$ ). The result is consistent with previous empirical literature. Sociologist used to argue that religion is an important aspect of culture, and norms that govern family pattern variations often are affected by the socio-religious climate in a given society (Lutz, 1987). Also, religiosity has been viewed as contributing to marital success or its appearance. Traditional religions stress the importance of children and the marital relationship. Finally, age and working status were not found to have association with marital happiness. 


\section{Conclusion}

Couple's communication was found to have the strongest predictor of marital happiness. However, the rest of the independent variables (sex, education, self-reported health, religiosity, place of residence, and family size) in the study were found to have a weak or very weak relationship with marital happiness. Also, family income, working status, and age were not found to have a statistical association with marital happiness. In summary, married couples who have a higher level of communication, self-reported health, education, and religiosity and lower family size and who are male and urban residents are more likely to be happy than those who have lower level of communication, education and religiosity and higher family size and who are female and rural residents.

A limitation of this study is that its analysis deals with Sharjah Emirate. No data were available in the FCS for other Emirates in the UAE. Thus, further research is needed to explore the determinants of marital happiness in the UAE and the Arab world through adding more independent variables in the analysis.

\section{References}

Aldous, J. and Woodberry, R. (1994). Gender, Marital Status, and the Pursuit of Happiness. Paper presented at the 56th Annual Meeting of the National Council on Family Relations, Minneapolis. November.

Amato, P.R., Johnson, D.R., Booth, A. and Rogers, S.J. (2003). Continuity and Change in Marital Quality Between 1980 and 2000. Journal of Marriage and Family, 65, 1-22. http://dx.doi.org/10.1111/j.1741-3737.2003.00001.x

Ball, R.E. and Robbins, L. (1984). Marital Status and Life Satisfaction of Black Men. Journal of Social and Personal Relationships, 1:459-470. http://dx.doi.org/10.1177/0265407584014004

Blood, R.O. and Wolfe, D.M. (1960). Husbands and Wives: The Dynamics of Married Living. New York: Free Press.

Campbell, A., Converse, P.E. and Rodgers, W.L. (1976). The Quality of American Life. New York: Russell Sage Foundation.

Corra, M., Houvounas, S., Carter, J.S. and Knox, D. (2008). Happiness in Marriage since the 1970's: Over Time Changes by Race and Gender. American Sociological Association, Annual Meeting, January 1.

Faulkner, R.A., Davay, M. and Davey, A. (2005). Gender-Related Predictors of Change in Marital Satisfaction and Marital Conflict. American Journal of Family Therapy, 33:61-83. http://dx.doi.org/10.1080/01926180590889211

Glenn, N.D. and Weaver, C.N. (1979). A note on family situation and global happiness. Social Forces, 57, 960-967.

Glenn, N.D. and Weaver C. (1978). A Multivariate, Multisurvey Study of Marital Happiness. Journal of Marriage and the Family, 40:269-282. http://dx.doi.org/10.2307/350758

Gurin, G., Veroff, J. and Feld, S. (1960). American View their Mental Health. NEW York: Baric Books.

Henry, R.G., Miller, R.B. and Giarrusso, R. (2005). Difficulties, Disagreements, and Disappoints in Late-Life Marriages (Older Couples Experience). International Journal of Aging and Human Development, 61, 243-265. http://dx.doi.org/10.2190/EF1G-PNXF-J1VQ-6M72

Hicks, M.W. and Platt, M. (1970). Marital Happiness. A Review of the Research in the Sixties, 32 (4), 553-574.

Kaufman, G. and Taniguchi, H. (2006). Gender and Marital Happiness in Later Life. Journal of Family Issues, 27, 735-757. http://dx.doi.org/10.1177/0192513X05285293

Kiecolt-Glaser, J.K. and Newtown, T.L. (2001). Marriage and Health: His and Hers. Psychological Bulletin, 127:472-503. http://dx.doi.org/10.1037/0033-2909.127.4.472

Komarvosky, M. (1962). Blue-Collar Marriage. New York: Random House.

Lee, K.S. and Ono, H. (2008). Specialization and Happiness in Marriage: A U.S-Japan. Social Science Research, 37(4), 1216-1234. http://dx.doi.org/10.1016/j.ssresearch.2008.02.005

Lewis-Beck, M. (1980). Applied Regression: An Introduction. Newbury Park: Soon Publications.

Lutz, W. (1987). Culture, Religion, and Fertility: A Global View. Genus, Vol. 43, Issue 3-4.

McLanahan, S. and Adams, J. (1987). Parenthood and Psychological Well-Being. pp. 237-257. In W. Scott (Ed.), Review of Sociology (Vol. 13, August). Palo Alto, CA: Annual Reviews, Inc. 
Michalos, A.C. (1985). Multiple Discrepancies Theory (MDT). Social Indicators Research, 16:347-413. http://dx.doi.org/10.1007/BF00333288

Navran, L. (1967). Communication and Adjustment in Marriage. Family Process, 6: 173-184. http://dx.doi.org/10.1111/j.1545-5300.1967.00173.x

Olson, D., Defrain, J., and Skogrand, L. (2010). Marriage and Families: Intimacy, Diversity, and Strengths. Mc Graw-Hill.

Olson. A. and Olson, D.H. (2001). Ten Traits of love. In J.R. Levine and H.Markman (Eds.), Why Do fools Fall in Love? Experiencing the Magic Mystery, and Meaning of Successful Relationships. San Francisco: Jossey Buss.

Richard, B.E. (1993). Children and Marital Happiness of Black Americans. Journal of Comparative Family Studies, 24 (2), 203-218.

Sandhya, S. (2009). The Social Context of Marital Happiness in Urban Indian Couples: Interplay of Intimacy and Conflict. Journal of Marital and Family Therapy, Vol. 35, No. 1, 74-96. http://dx.doi.org/10.1111/j.1752-0606.2008.00103.x

Scanzoni, J.H. (1977). The Black Family in Modern Society: Patterns of Stability and Security. Chicago: University of Chicago Press.

Stack, S. and Eshleman. (1998). Marital Status and Happiness: A 17-Nation Study. Journal of Marriage and the Family, 60, 527-536. http://dx.doi.org/10.2307/353867

Strong, Bryan and Devault, Christine. (1995). The Marriage and Family Experience. New York: West Publishing Company.

Terman, L.M. (1938). Psychological Factors in Marital Happiness. New York: McGraw-Hill.

Umberson, D. and Gove, W. (1989). Parenthood and Psychological Well-Being: Theory, Measurement, and Stage in the Family Life Course. Journal of Family Issues, 10:440-462. http://dx.doi.org/10.1177/019251389010004002

Vogt, P.W. (1999). Dictionary of Statistics and Methodology: A Nontechnical Guide for the Social Sciences. Thousand Oaks: Sage Publications.

Waite, L.J. and Gallagher, M. (2000). The Case for Marriage: Why Married People Are Happier, Healthier, and Better off Financially. Doubleday.

Ward, R.A. (1993). Marital Happiness and Household Equity in Later Life. Journal of Marriage and the Family, 55, 427-438. http://dx.doi.org/10.2307/352813

Table 1. Distribution of Married Couples by Socio-Demographic Characteristics $(\mathrm{N}=1136)$

\begin{tabular}{|c|c|c|c|}
\hline \multicolumn{2}{|l|}{ Variables } & Frequency & $\%$ \\
\hline \multirow[t]{3}{*}{ Sex } & 1. Male & 780 & 68.7 \\
\hline & 2. $\quad$ Female & 356 & 31.3 \\
\hline & Total & 1136 & $100 \%$ \\
\hline \multirow[t]{3}{*}{ Place of residence } & 1. Urban & 1012 & 89.1 \\
\hline & 2. $\quad$ Rural & 124 & 10.9 \\
\hline & Total & 1136 & $100 \%$ \\
\hline \multirow[t]{5}{*}{ Age } & 1. $18-29$ & 284 & 25 \\
\hline & 2. $30-41$ & 448 & 39.5 \\
\hline & 3. $42-53$ & 324 & 28.5 \\
\hline & 4. $\quad 54-64$ & 80 & 7 \\
\hline & Total & 1136 & $100 \%$ \\
\hline \multirow[t]{3}{*}{ Working status } & 1. Working & 860 & 75.7 \\
\hline & 2. Not working & 276 & 24.3 \\
\hline & Total & 1136 & $100 \%$ \\
\hline Total family income * & 1. Less than 10000 & 88 & 7.8 \\
\hline
\end{tabular}




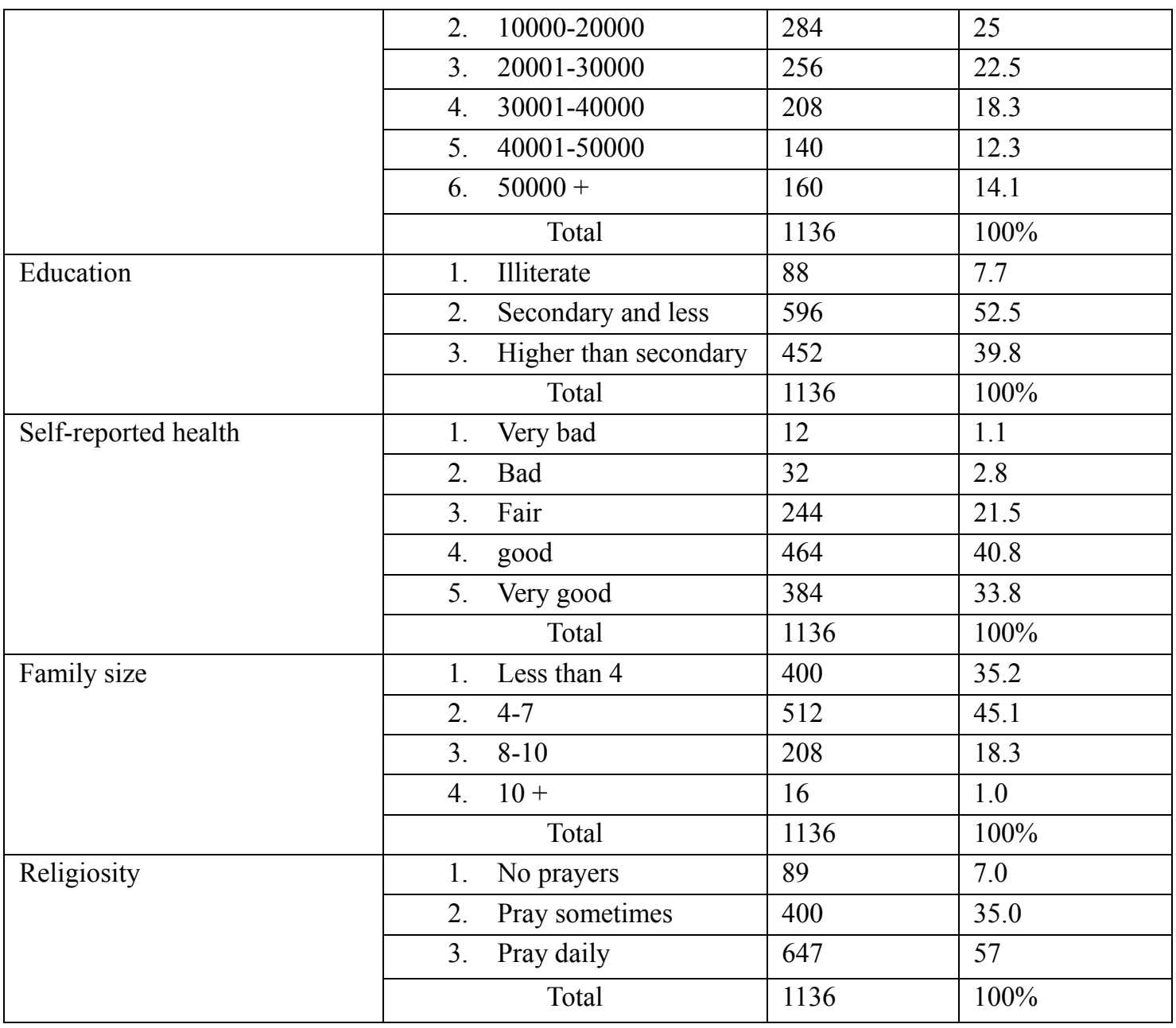

*A dollar is equal to 3.6 dirhams.

Table 2. Ranges, Means, and Standard Deviation of the Dependent and Independent Variables $(\mathrm{N}=1136)$

\begin{tabular}{|l|l|l|l|}
\hline Variable & Range & Mean & SD \\
\hline Dependent variables & & & \\
\hline Marital happiness & $1-3$ & 2.176 & .637 \\
\hline Independent variables & & & \\
\hline Sex & $1-2$ & 1.313 & .464 \\
\hline Place of residence & $1-2$ & 1.109 & .311 \\
\hline Age & $1-4$ & 2.176 & .886 \\
\hline Education & $1-3$ & 2.320 & .610 \\
\hline Working status & $1-2$ & 1.243 & .429 \\
\hline Family income & $1-6$ & 3.447 & 1.51 \\
\hline Family size & $1-4$ & 1.859 & .756 \\
\hline Religiosity & $1-3$ & 2.311 & .700 \\
\hline Self evaluation of health & $1-5$ & 4.035 & .871 \\
\hline Couple's communication* & $10-50$ & 38.253 & 8.99 \\
\hline
\end{tabular}

*Couple's communication index consists of 10 items with Likert scale answer for each item. The index has been scaled from 10 (low communication) to 50 (high communication), with alpha reliability of 0.80 . 
Table 3. Distribution of Married Couples According to their Marital Happiness Categori

\begin{tabular}{|l|l|l|}
\hline Marital happiness & F & $\%$ \\
\hline Very happy & 348 & 30.6 \\
\hline Pretty happy & 640 & 56.3 \\
\hline Not happy & 148 & 13.0 \\
\hline Total & 1136 & 100 \\
\hline
\end{tabular}

Table 4. Correlation Matrix of the Independent Variables in the study $(\mathrm{N}=1136)$

\begin{tabular}{|l|l|l|l|l|l|l|l|l|l|l|}
\hline Variables & 1 & 2 & 3 & 4 & 5 & 6 & 7 & 8 & 9 & 10 \\
\hline Sex & - & & & & & & & & & \\
\hline Age & $-0.144^{* *}$ & - & & & & & & & & \\
\hline Education & -0.37 & $-0.435^{* *}$ & - & & & & & & & \\
\hline Working status & $0.450^{* *}$ & .0550 & $-0.324^{* *}$ & - & & & & & & \\
\hline Residence & $0.250^{* *}$ & -0.057 & $-0.094^{* *}$ & $0.276^{* *}$ & - & & & & & \\
\hline Family size & 0.020 & $0.558^{* *}$ & $-0.398^{* *}$ & $0.145^{* *}$ & 0.053 & 0.041 & - & & & \\
\hline Family income & $-0.089^{* *}$ & $0.204^{* *}$ & $-0.065^{*}$ & $-0.099^{* *}$ & $-0.192^{* *}$ & $-0.077^{* *}$ & $0.276^{* *}$ & - & & \\
\hline $\begin{array}{l}\text { Self-reported } \\
\text { health }\end{array}$ & $0.190^{* *}$ & $-0.269^{* *}$ & $0.272^{* *}$ & $0.100^{* *}$ & $0.180^{* *}$ & $-0.085^{* *}$ & $-1.33^{* *}$ & $-0.077^{* *}$ & - & \\
\hline $\begin{array}{l}\text { Couple's } \\
\text { communication }\end{array}$ & $0.097^{* *}$ & $-0.064^{*}$ & $0.133^{* *}$ & 0.017 & $0.097^{* *}$ & 0.033 & $-0.088^{* *}$ & -0.045 & $0.359^{* *}$ & - \\
\hline
\end{tabular}

Table 5. Summary of Multiple Effects of Explanatory Factors on Marital Happiness

\begin{tabular}{|l|l|l|l|l|l|}
\hline Variables & B & S.E & Beta & T & Sig T \\
\hline Sex & 1.34 & 0.043 & 0.098 & 3.108 & 0.002 \\
\hline Age & 0.003 & 0.002 & 0.050 & 1.762 & 0.078 \\
\hline Education & 0.022 & 0.009 & 0.067 & 2.451 & 0.014 \\
\hline Working status & 0.033 & 0.049 & 0.022 & 0.669 & 0.504 \\
\hline Place of residence & 0.222 & 0.048 & 0.109 & 4.624 & 0.000 \\
\hline Family size & -0.023 & 0.008 & -0.083 & -2.977 & 0.003 \\
\hline Family income & 4.61 & 0.000 & 0.012 & 0.534 & 0.594 \\
\hline Self-reported health & .118 & 0.018 & 0.162 & 6.402 & 0.000 \\
\hline Couple communication & 0.042 & 0.002 & 0.599 & 25.492 & 0.000 \\
\hline Religiosity & 1.44 & 0.050 & 0.054 & 2.360 & 0.018 \\
\hline
\end{tabular}

$\mathrm{R}^{2}=0.470, \mathrm{~F}=99.576, \mathrm{P}=000$ 